\title{
PERSPECTIVAS HISTÓRICAS E CONCEPÇÕES DE QUALIDADE E ACESSO AO ENSINO SUPERIOR A DISTÂNCIA NO BRASIL*
}

\author{
Simone Maria Martins** \\ Maria Luisa Furlan Costa***
}

\section{RESUMO}

O objetivo deste artigo consiste em apresentar os resultados de uma pesquisa desenvolvida no Programa de Pós-Graduação em Educação da Universidade Estadual de Maringá, que apontam a história da educação a distância no Brasil, especialmente o Ensino Superior público. Busca-se articular a contribuição das políticas públicas para o acesso ao Ensino Superior de qualidade com os pressupostos de pesquisadores que apontam questões conceituais sobre a qualidade de cursos em nível superior nessa modalidade de ensino. Como ponto de reflexão, cita-se a articulação entre as questões legais e os avanços já alcançados em termos de acesso ao Ensino Superior e sua contribuição ante as necessidades que emergem no Brasil para os avanços da democratização do Ensino Superior. Nas considerações finais, segue uma breve retrospectiva da importância das políticas públicas educacionais, após a redemocratização do país, indicando o quanto a inserção desta modalidade vem contribuindo para o acesso ao ensino superior público.

Palavras-chave: História, Educação Superior, Modalidade a Distância, Qualidade.

\section{HISTORICAL PERSPECTIVES AND CONCEPTS OF QUALITY AND ACCESS TO HIGHER EDUCATION DISTANCE IN BRAZIL}

\begin{abstract}
The purpose of this article is to present the results of a study on the literature, discussed in the dissertation of the authors, pointing to the history of distance education in Brazil, especially public higher education. Seeks to articulate the contribution of public policies for access to quality higher education with the assumptions of researchers, pointing conceptual questions about the quality of courses in higher education in this modality. As a point of reflection, cite the relationship between the legal and the progress already achieved in terms of access to higher education and its contribution compared to the needs that emerge in Brazil to advances in democratization of higher education. In closing remarks, follows a brief review of the importance of educational policies, after the democratization of the country, showing how the insertion of this modality has been contributing to access to public higher education.
\end{abstract}

Keywords: History, Higher Education, Distance Learning, Quality.

\section{Introdução}

O objetivo deste artigo é discorrer acerca da forma como foi desenhada a história da educação a distância no Ensino Superior brasileiro visando à democratização do acesso à educação pública, buscando compreender e levantar as concepções que norteiam e regem a questão da qualidade em cursos superiores nessa modalidade no Brasil. Nesse sentido, primeiramente apresenta-se um breve histórico das tentativas de implementação da EaD no Ensino Superior até a sua efetivação por meio de instrumentos legais que sustentam sua implementação nas universidades públicas. 
Considerando a importância de se apresentar concepções conceituais que contribuam de modo significativo, por meio de pesquisa bibliográfica e documental, apontar-se-á o que os estudiosos de EaD no Brasil pensam sobre a qualidade do Ensino Superior brasileiro nessa modalidade, indicando os principais pontos destacados por eles quanto aos aspectos de qualidade, bem como o que julgam necessário e essencial, para que a modalidade a distância atenda as necessidades de qualidade.

Por meio de dados estatísticos, apresentar-se-á de que forma a modalidade a distância no Ensino Superior, vem contribuindo para o acesso às vagas públicas. Nas considerações finais, destaca-se a importância dos avanços históricos, pontuando como primordial a questão conceitual da qualidade, destacando-se como esta modalidade têm colaborado no acesso à educação pública.

\section{Apontamentos Históricos do Ensino Superior a Distância}

A modalidade de educação a distância no Ensino Superior somente foi reconhecida oficialmente no Brasil no final do século XX, mais precisamente na década de 1990, quando, após o processo de redemocratização do país, concretizado com a Constituição Federal de $1988^{1}$, a "constituição cidadã" abriu as portas para um novo cenário de educação, emergindo a necessidade de uma nova lei educacional, nascendo posteriormente a Lei de Diretrizes e Bases da Educação Nacional - LDBEN 9394/1996².

Ao longo desse retrospecto histórico, aborda-se o percurso das tentativas legais, descrito na pesquisa de Pimentel (2006), qual destaca que se iniciou em 1972, quando surgiu o interesse de alguns parlamentares na implantação de uma Universidade Aberta no Brasil motivados pelo alto crescimento de cursos superiores a distância, em diversos países durante esse período, com destaque para a criação da Open University ${ }^{3}$ na Inglaterra, em 1969.

Dessa forma, o Governo Federal instituiu uma comissão para analisar a viabilidade de implantação de uma instituição para a oferta de cursos a distância no país; todavia, o sucesso obtido na Inglaterra com seus cursos superiores a distância foi insuficiente para convencer o Conselho Federal de Educação e o Governo Federal a aprovarem um sistema de Ensino Superior a distância no Brasil (ALVES, 2012).

Mesmo com parecer desfavorável do Conselho Federal de Educação e do Governo Federal, a primeira tentativa de implantação de uma universidade aberta e a distância surgiu por meio do Projeto n. 1.878, de 1974, que buscava legalizar e implantar a Universidade Aberta. Na tramitação do Projeto, o Conselho Federal de Educação emitiu o Parecer n. 2.780/1974, manifestando-se contra a implantação de uma instituição que pudesse ofertar cursos em uma modalidade distinta do ensino presencial. Esse Parecer influenciou decisivamente a rejeição e o arquivamento do Projeto, o qual foi reapresentado em 1977 com o n. 3.700/1977 e mais uma vez arquivado (ALVES, 2007).

Segundo Pimentel (2006), durante a década de 1970 somaram-se ao todo setenta Projetos de Lei (PL) para a concretização de um programa que contemplasse a criação da Universidade Aberta no Brasil.

Na década de 1980, de acordo com Alves (2007), surgiu outra tentativa de implantação da EaD, tanto que o Conselho Federal de Educação (CFE) autorizou a criação do programa de Pós-Graduação a Distância (POSGRAD), por intermédio do Instituto de Radiodifusão Educativa da Bahia (IRDEB), na Universidade Federal do Rio de Janeiro (UERJ) e no Centro Técnico de Brasília (CETEB). Essa iniciativa utilizou-se da 
radiodifusão como ferramenta básica para a intermediação dos atores, considerando o quanto era difícil naquele momento a disposição de recursos tecnológicos e midiáticos.

Em 1983, surge mais uma tentativa de implantação da Universidade Aberta, com o Projeto de Lei n. 1.751/1983 apresentado pelo deputado Clark Planton, que ressaltava as possibilidades de ampliação de acesso ao Ensino Superior no Brasil por meio da Universidade Aberta (PIMENTEL, 2006).

No ano de 1985, o assessor do Ministro da Desburocratização, João Batista Araújo e Oliveira, pronunciou seu parecer sobre a Universidade Aberta, pontuando a necessidade da implantação de propostas inovadoras para uma educação permanente, principalmente devido à demanda existente naquele período, além da incapacidade que o modelo convencional de educação revelava em suas respostas qualitativas e quantitativas para atendimento da demanda existente. Contudo, o país ainda teve que passar mais vinte anos para que de fato surgisse a definitiva legalização da oferta dessa modalidade (PIMENTEL, 2006).

Pimentel (2006) indica que por intermédio do Conselho Federal de Educação foi criada, em 1986, uma comissão constituída de sete especialistas indicados pelo Ministério da Educação (MEC), os quais estudaram as possibilidades de criação da Universidade Aberta, com a intermediação de estudos por correspondência e frequência livre; todavia o projeto mais uma vez foi arquivado. Nesse mesmo ano, o deputado Paulo Lustosa apresentou o Projeto de Lei n. 8.571 propondo a Fundação Instituto de Ciências Puras Aplicadas (FUNCEVE), de direito privado e sem fins lucrativos. (PIMENTEL, 2006, p. 71).

Já em 1987, o deputado Lucio Alcântara propôs um novo projeto para a criação da Universidade Nacional de Ensino a Distância (UNED), com a apresentação do Projeto de Lei n. 203/1987, o qual tratava da oferta de cursos de extensão (PIMENTEL, 2006).

Nesse percurso de uma longa discussão para o desencadeamento do processo institucional da $\mathrm{EaD}$ no Brasil, com a influência dos reflexos da conquista do processo democrático e a instauração da nova Constituição da República Federativa do Brasil, em 1988, houve um pronunciamento importante sobre a ideia de uma Universidade Aberta. Dessa vez, de acordo com Pimentel (2006), a iniciativa veio por intermédio de um membro do Conselho Federal de Educação (CFE), Arnaldo Niskier, que argumentou que a modalidade de ensino a distância poderia beneficiar todo o sistema educacional brasileiro devido ao processo de modernização do país, colaborando ainda para o aperfeiçoamento profissional.

Esse processo de mudança política brasileira impulsionou e influenciou definitivamente a discussão de políticas norteadoras para a conquista de leis que promovessem o surgimento dessa forma de ensino nas universidades brasileiras. Ademais, surgiam cada vez mais parlamentares favoráveis aos investimentos em uma universidade a distância, particularmente aqueles envolvidos diretamente com a educação, com ênfase para o memorável professor e político Darcy Ribeiro ${ }^{4}$.

Na década de 1990, representantes do Governo Federal apresentaram uma proposta de criação da Universidade Aberta do Brasil vinculada ao Ministério da Educação (MEC), com a coordenação e supervisão do Instituto Nacional de Estudos e Pesquisas Educacionais (INEP), em parceria com a Fundação Centro Brasileiro de Televisão Educativa (FUNTEVE). Apesar de ser uma proposta consistente, com o envolvimento e consentimento de diversos órgãos públicos, os quais promoveram inúmeras discussões, mais uma vez o resultado terminou com o arquivamento do projeto (PIMENTEL, 2006).

Após anos de discussões e do surgimento de diversas propostas para a criação de uma Universidade Aberta, fica evidente que somente com a LDBEN n. 9394/1996 a EaD 
teve respaldo e amparo legal para que as universidades pudessem articular seus cursos na modalidade a distância.

Conforme se assinalou anteriormente, um dos maiores percussores desse modelo estrutural de educação na modalidade a distância em nível superior foi Darcy Ribeiro, relator da matéria e forte influente na elaboração da LDBEN atual, que com seu trabalho contribuiu para a construção da universidade a distância atualmente presente em nosso país. Esse intelectual esteve diretamente ligado à consolidação das políticas educacionais para o século XXI, somando inúmeros esforços para a idealização e criação da Universidade de Brasília (UNB), que influenciou decisivamente na criação do programa Universidade Aberta do Brasil (UAB).

Para compreender o percurso legal que ampara o processo relativo à Universidade Aberta do Brasil, pós-LDBEN n. 9394/1996, se faz necessário compreender seu histórico e o que significa o termo UAB, que não se trata de uma universidade propriamente dita, mas de um sistema criado pelo Governo Federal, por meio da Secretaria de Ensino a Distância $(\mathrm{SEED})^{5}$, pertencente ao MEC, que mediante editais articula e convenia prefeituras para a criação da infraestrutura de polos, juntamente com as Instituições Púbicas de Ensino Superior, para a oferta de cursos de graduação, aperfeiçoamento e especialização na modalidade a distância.

Ao traçar a história da educação a distância a partir desse novo cenário, um documento importante que ofereceu consistência na estruturação dessa modalidade foi o Plano Nacional de Educação (PNE), o qual abre possibilidade para a criação de:

"um amplo sistema interativo de educação a distância, utilizando-o, inclusive, para ampliar as possibilidades de atendimento nos cursos presenciais, tanto os regulares como os de educação continuada" (BRASIL, 2012b, p. 74).

Durante o trajeto para a legalização do Ensino Superior a Distância, surge a Portaria n. 2.253/2001, revogada pela Portaria n. 4.059/2004, com base no Artigo 80 da Lei n. 9394/1996 e no Decreto n. $2.494 / 1998^{6}$, que no uso de suas atribuições legais institui a possibilidade da oferta de disciplinas semipresenciais em sua organização pedagógica e curricular, com atividades didáticas centradas na autoaprendizagem, com mediação de recursos tecnológicos de informação e comunicação remota (BRASIL, 1998).

No Decreto n. 5.622/2005 , a educação a distância no Brasil é caracterizada como modalidade educacional que visa a procedimentos didático-pedagógicos com o uso de meios e tecnologias de informação e comunicação, proporcionando aos professores e alunos atividades em lugares e tempos diversos de acordo com a realidade local (BRASIL, 2005a, p. 1).

Outro documento para a consolidação da modalidade a distância no Brasil é o Decreto n. $5.800^{8}$, de 8 de junho de 2006, que destaca a articulação e integração de Instituições de Ensino Superior, Municípios e Estados com vistas à democratização, expansão e interiorização da oferta de Ensino Superior público e gratuito no país, além do desenvolvimento de projetos de pesquisa e de metodologias inovadoras de ensino, preferencialmente para a área de formação inicial e continuada de professores da educação básica.

Com o Decreto n. 6.303/2007, a educação a distância tem em sua organização metodológica a obrigatoriedade de momentos presenciais, os quais exigem do estudante: realização de avaliações, cumprimento de estágios previstos na proposta curricular, defesa 
de trabalhos de conclusão de curso, e atividades de laboratório quando também constar no currículo do curso (BRASIL, 2012a).

Dessa forma, o Ministério da Educação criou uma infraestrutura para o funcionamento da UAB envolvendo todas as instâncias, desde a esfera federal, estadual e municipal. Pode-se afirmar que a LDB foi o impulso necessário para a implantação de cursos em nível superior na modalidade EaD no Brasil. Segundo Alves:

Durante toda a vigência da legislação educacional anterior à atual Lei de Diretrizes e Bases da Educação Nacional (Lei nº 9.394/1996), não houve sequer um curso superior de graduação autorizado para funcionar com uso de técnicas de educação a distância. (ALVES, 2007, p.1).

Para finalizar esse processo histórico que consolidou a educação a distância no Brasil, em 2007 os Referencias de Educação a Distância são publicados, documento que apesar de não ter força de lei, impera soberanamente entre os critérios e exigências para aprovação de um curso nessa modalidade.

\section{Apontamentos Conceituais da Qualidade do Ensino Superior a Distância}

Tratando-se da discussão relativa à qualidade da Educação a Distância, alguns apontamentos de referenciais teóricos se fazem pertinentes, com destaque para autores renomados no cenário brasileiro. Ampliando a abrangência e a dimensão dessa discussão conceitual, julga-se substancial a inserção de apontamentos de referenciais teóricos que contribuam para um maior esclarecimento do que se discute e se determina como parâmetros de qualidade em cursos na modalidade a distância em nível superior.

Inicialmente, é importante evidenciar que uma das grandes dificuldades da $\mathrm{EaD}$ tem sido a sua posição de baixo prestígio, considerada por muito tempo como uma solução paliativa, emergencial ou marginal diante dos sistemas convencionais de ensino. Ademais, essa modalidade de ensino ainda é tida por alguns como a última opção para quem não conseguiu acessar o Ensino Superior. Corroborando Belloni (2009), essas concepções distorcidas relativas a EaD geram dúvidas sobre a qualidade do ensino, com uma tendência a enfatizar-se os fracassos, mesmo com grande sucesso e prestígio de experiências bem sucedidas na Europa pelas grandes Universidades Abertas. No caso do Brasil, essa situação gera descredibilidade da EaD, sendo possível acarretar problemas de financiamento, e se reflete diretamente na qualidade.

Alonso (2010) aponta que o termo qualidade pressupõe que essa referência converteu-se em um critério para afirmar ou negar a modalidade a distância. A autora vai mais além ao salientar que para que se tenha qualidade na educação, faz-se necessário o princípio da democratização, que defende o acesso e a permanência de qualidade no Ensino Superior público na modalidade a distância. Mais do que isto, indica a competência do professor como fator primordial para a qualidade (ALONSO, 2012).

Matias-Pereira (2010) parte do pressuposto de que o modelo de EaD sustentado pelas tecnologias da informação e comunicação permite incluir, por meio de uma educação de qualidade, um grande número de pessoas impossibilitadas de frequentar um ambiente presencial, além das exigências de estimular a inclusão digital.

Segundo Moran (2008), a EaD no Brasil tem vários significados, que correspondem a concepções e necessidades distintas. Entre as denominações utilizadas para caracterizar a $\mathrm{EaD}$ ou as finalidades prosseguidas encontram-se a educação continuada, o treinamento 
em serviço, a formação supletiva, a formação profissional, a qualificação docente, a especialização acadêmica e a complementação dos cursos presenciais.

Ao analisar os referenciais de qualidade, Moran (2008) afirma que é necessária uma reformulação nas políticas públicas em $\mathrm{EaD}$, priorizando os ambientes virtuais de aprendizagem. Da mesma forma, na acepção do autor, os polos presenciais não precisam ser unívocos, ou seja, justificam-se apenas quando haja necessidade. Acrescenta o autor que a qualidade da $\mathrm{EaD}$ se pautaria na potencialização dos ambientes virtuais de aprendizagem, permitindo que a infraestrutura dos polos tenha mais flexibilidade e que estes não sejam tão padronizados.

Além da questão dos recursos tecnológicos e da tutoria anteriormente indicados como fatores de qualidade, outro ponto que merece ênfase refere-se aos polos de apoio presencial. Costa (2010) pondera que o polo de apoio presencial é o ponto de equilíbrio do Sistema UAB porque possibilita a garantia da qualidade dos cursos ofertados pelas Instituições de Ensino Superior. Para a autora, a infraestrutura dos polos, ou seja, o espaço físico e os recursos humanos são os principais responsáveis pela operacionalização de todo o trabalho pedagógico e administrativo.

Alves (2012) acredita que a EaD tem a possibilidade de ofertar qualidade dos serviços devido às possibilidades disponibilizadas pelas novas tecnologias de informação e comunicação que abrem novos processos de ensino-aprendizagem a distância. $\mathrm{O}$ autor pontua que essas novas abordagens surgiram em decorrência da utilização crescente de multimídias e ferramentas de interação, tornando possível acessar muitas informações, em um ambiente interativo e colaborativo, envolvendo pessoas geograficamente distantes.

Entretanto, é importante relembrar o que Vilaça (2012) adverte sobre a questão da tecnologia, asseverando que por si só não é suficiente para se garantir qualidade ao ensino, e que isso depende de uma ampla variedade de fatores, como exemplifica ao afirmar que é possível ser "tradicional" em EaD da mesma forma como é possível ser "inovador" no ensino "tradicional" (VILAÇA, 2012, p. 8). O fator tecnologia realmente não garante que se faça diferença quando se trata da educação a distância, como argumenta o autor.

Guimarães (2012) cita outro aspecto interessante ao discutir qualidade quando aponta uma vantagem nos cursos em $\mathrm{EaD}$, o material didático. $\mathrm{O}$ autor defende que os materiais de aprendizagem devem ser produzidos por professores-pesquisadores competentes, e que os conteúdos devem ser adequados em sua forma e apresentação, preparados por uma equipe especializada em novas tecnologias e nas linguagens das mídias, com alta qualidade científica e pedagógica. Nesse aspecto, o autor não só destaca a relevância do material didático, mas também de quem o produz, além de todos os fatores que contribuem para a qualidade da elaboração, linguagem e diagramação do material, sejam livros, vídeos, guias, dentre outros.

Do ponto de vista político-pedagógico, com a utilização dessas novas tecnologias da informação e comunicação, surge um novo perfil docente e discente, exigindo a integração do uso de tecnologias de multimídia, atitudes críticas perante a comunicação e o aprimoramento do processo comunicacional, possibilitando a democratização de saberes e o desenvolvimento de capacidades intelectuais.

Maia; Mattar (2007) esclarecem que o desenvolvimento da EaD criou um novo tipo de personagem na sociedade, que pode ser batizado de "aprendiz virtual". Em EaD, o centro do processo de ensino e aprendizagem não é mais o interesse do professor na disciplina, mas sim o que o aluno precisa aprender. O aprendiz, portanto, deve ser levado em conta na fase do planejamento e da implementação da experiência de aprendizado a distância e não apenas no final, quando o conteúdo de um curso a distância já estiver pronto. 
A educação a distância exige, portanto, um aprendiz autônomo e independente, mais responsável pelo processo de aprendizagem e disposto à autoaprendizagem, pois a alteração da cultura do ensino para a cultura da aprendizagem fez com que o estudo passasse a ser autoadministrado e automonitorado por um aprendiz autônomo (MAIA; MATTAR, 2007).

Nesse novo cenário e diante de tantos recursos tecnológicos disponíveis, muitos países buscam novas possibilidades para oferecer educação de qualidade. Sousa (2012) considera que a aprendizagem independente será a grande estratégia da educação, porque muitos aprenderão por meio do computador e as teleconferências serão um veículo excelente para trazer os melhores especialistas do mundo à sala de aula.

Nesta abordagem conceitual, buscou-se apresentar diversas formas de se retratar a questão da qualidade nos cursos a distância, e o resultado indicou diversos fatores, dentre eles a importância de professores especializados em $\mathrm{EaD}$, o ambiente virtual de aprendizagem, os recursos tecnológicos, além do fundamental para o sucesso da $\mathrm{EaD}, \mathrm{o}$ aluno e sua perspectiva de aprendizagem, o qual foi denominado aprendiz virtual.

\section{Acesso ao Ensino Superior Público e a Educação a Distância}

Dados publicados em 2007 no Anuário Brasileiro de Educação a Distância $(A B R A E A D)^{9}$ informam que $42 \%$ dos professores da Educação Básica não possuem diploma de curso superior. Nesse contexto, mais de dois terços (72\%) dos cursos da UAB são voltados à formação de professores, grande parte voltada para um público-alvo que não dispõe de instituições de Ensino Superior nas proximidades de sua residência. Dessa forma, a adoção da modalidade de EaD deverá apresentar especial impacto positivo no atendimento de demandas de formação ou capacitação de mais de um milhão de docentes para a Educação Básica.

O propósito da UAB consiste em sistematizar ações, programas, projetos e atividades pertencentes às políticas públicas voltadas para a ampliação e interiorização da oferta do Ensino Superior gratuito e de qualidade no Brasil. A UAB vincula uma parceria entre consórcios públicos que envolvem os três níveis governamentais (federal, estadual e municipal), além da participação das universidades públicas. Não se trata, por conseguinte, de uma nova instituição de ensino, mas de articular as já existentes, com a proposta de socializar oportunidades de Ensino Superior público de qualidade aos municípios brasileiros (BRASIL, 2006).

Como uma consequência imediata da criação do Sistema UAB, o Censo da Educação Superior, publicado em 2007, mostra que houve um grande crescimento nos cursos de educação a distância, pois entre os anos de 2003 até 2006 a oferta de cursos cresceu em $571 \%$, e o número de matrículas saltou para $315 \%$. Nesse período, o número de alunos pertencentes ao Ensino Superior a distância passou de 2,6\% para 4,4\% (BRASIL, 2012).

Comparando-se o ensino presencial e o ensino a distância, os números comprovam a expansão do Ensino Superior a distância. Segundo o INEP (2002, 2003, 2004, 2005, 2006), a oferta de cursos no Ensino Superior presencial teve um crescimento de aproximadamente $64,8 \%$, enquanto que nesse mesmo período o crescimento do ensino superior a distância cresceu 758\% (CORTINHAS, 2012).

De acordo com Anuário Brasileiro de Educação a Distância (ABRAEAD) publicado em 2008, no período de 2005 até 2007 o número de alunos em $\mathrm{EaD}$ cresceu $213 \%$, e o de instituições credenciadas, 54,8\%. Somente em 2011 esse crescimento foi de 
$24,9 \%$ em relação ao número de alunos e de $14,2 \%$ de novas instituições credenciadas. Esses dados demonstram que mesmo após as iniciativas em grande escala em todo o país para implantação da modalidade a distância nas universidades, esse ritmo, embora em menor proporção, indica que a EaD não parou de crescer no Brasil (ABRAEAD, 2008).

Dados do Anuário Estatístico de 2007 revelam que existem 430 mil alunos na graduação na modalidade em $\mathrm{EaD}$, somados a um crescimento de $356 \%$ nos cursos de graduação e pós-graduação nos últimos quatro anos no país. Esse crescimento se deve, entre outros, a fatores como mudança de visão e valorização da $\mathrm{EaD}$ como forma de socializar o acesso ao Ensino Superior, ampliação do número de cursos oferecidos, que nos últimos quatro anos cresceram $600 \%$ e a necessidade crescente de atualização dos trabalhadores do país.

Atualmente, as políticas públicas do Ministério da Educação definem que a UAB é um programa da Diretoria de Educação a Distância (DED) vinculado à Coordenação de Aperfeiçoamento de Pessoal do Ensino Superior (Capes), que atribui suas competências por intermédio de suas coordenações divididas entre as pastas de fomento e articulação de cursos, infraestrutura de polos, tecnologias educacionais e planejamento financeiro.

Com esses dados, é possível evidenciar esforços empreendidos por parte das universidades públicas, em conjunto com o Governo Federal, em ampliar a oferta de vagas na esfera pública para atender tanto a demanda de professores em exercício quanto a comunidade em geral que necessita dar continuidade aos estudos ingressando no Ensino Superior.

Ao analisar os dados estatísticos já referidos, é possível afirmar que a educação a distância, por intermédio da UAB, abriu grande possibilidade e apontou os impactos positivos em relação ao acesso à educação superior. Isso se deve, principalmente, ao fato de que as instituições federais e estaduais de Ensino Superior apresentam potencialidades rumo à democratização de seus cursos, o que se comprova pela existência de um imenso espaço para o fomento constante da pesquisa científica.

Quanto as metas referente a Educação a Distância, contidas no Plano Nacional de Educação (PNE), Dourado (2011) descreve os avanços alcançados na EaD no Ensino Superior, apontando que os indicadores revelam que essa modalidade expandiu-se significativamente. $\mathrm{O}$ autor afirma inclusive que, apesar dos limites da população brasileira no acesso as tecnologias de informação e comunicação, os dados acenam uma notória expansão da $\mathrm{EaD}$ em todos os níveis desta modalidade.

Vale por fim ressaltar que, a modalidade a distância vem suprir uma emergencial necessidade de uma educação inovadora e mediada pelo uso das tecnologias, conforme Dermeval Saviani $(2009$, p. 20) reconhece: “o ensino a distância, nas condições atuais do avanço tecnológico, é um importante auxiliar do processo educativo".

\section{Considerações Finais}

As políticas públicas voltadas ao acesso e à qualidade da educação a distância no Ensino Superior público brasileiro vêm buscando transformar o cenário atual, principalmente quando o assunto são as dificuldade de acesso às vagas públicas no país. Vale ressaltar que o Brasil inclui no Ensino Superior pouco mais de 12\% dos alunos que concluem anualmente o Ensino Médio.

Por isso, ao se tratar da qualidade da EaD neste artigo, considerou-se importante destacar a ampliação de cursos ofertados nessa modalidade, além do imenso salto de ingresso ao Ensino Superior mediante a educação a distância. Constatam-se os nítidos 
avanços que essa modalidade vem acrescentando para a democratização ao acesso ao Ensino Superior no Brasil.

Passados mais de trinta anos de tentativas para a implementação da modalidade a distância no Ensino Superior, somente com os reflexos de um novo cenário político (pósconstituição de 1988) foi que o Brasil abriu, em seus aspectos legais, as possibilidades concretas para a consolidação dessa modalidade.

Diante desse novo cenário educacional brasileiro, nascem as diretrizes para a Educação a Distância, além do sistema Universidade Aberta do Brasil, como forma de fortalecer as instituições públicas para a oferta de cursos nessa modalidade. As diretrizes para a EaD de 2005 abrem um dispositivo, exigindo que se construam referenciais de qualidade para o Ensino Superior exclusivamente voltados para a modalidade a distância.

Portanto, todos esses instrumentos legais foram válidos e essenciais, reforçando a importância em se dinamizar e ampliar a oferta de cursos em nível superior, algo tão sério e emergencial para a melhoria da condição educacional na sociedade brasileira.

No campo conceitual, as abordagens apresentadas propuseram-se a apontar os principais aspectos objetos de aferição de qualidade na educação a distância, abrindo diversas formas de se pensar e propor qualidade, que vai desde a necessidade de professores capacitados continuamente para a modalidade a distância, que exige muito aperfeiçoamento no uso dos recursos tecnológicos, até a importância da infraestrutura de polos, além das necessidades administrativas, e principalmente, uma educação voltada para a aprendizagem do aluno, e não mais somente para o ensino do professor.

Reitera-se a relevância da associação de alguns autores à questão da qualidade, ao reforçarem a potencialidade quanto ao uso do ambiente virtual de aprendizagem, além do acesso e interação aos recursos tecnológicos, durante o processo de aprendizagem dos alunos na modalidade a distância. Um fator extremamente positivo diante das necessidades da atual sociedade, na era dos avanços nas tecnologias de informação e comunicação.

Por fim, em termos de concepções conceituais referentes à qualidade, cabe também ao acadêmico da modalidade a distância aproveitar-se de todas essas ferramentas que estão à sua disposição motivando-os a agirem como alunos autônomos e críticos.

Espera-se que todos esses esforços institucionais ganhem cada vez mais força e espaço, para a consolidação da educação a distância como forma de democratizar o acesso e a qualidade do Ensino Superior público, tomando como base o próprio status que as universidades públicas demandam quanto à educação de qualidade.

\section{Referências}

ABRAEAD. Anuário Brasileiro Estatístico de Educação Aberta e a Distância, 2007. Coordenação: Fábio Sanchez. 3. ed. São Paulo: Instituto Monitor, 2007.

ABRAEAD. Anuário Brasileiro Estatístico de Educação Aberta e a Distância, 2008. Coordenação: Fábio Sanchez. 4. ed. São Paulo: Instituto Monitor, 2008.

ALONSO, Kátia Morosov. A expansão do ensino superior no Brasil e a EaD: dinâmicas e lugares. Educ. Soc. [online]. 2010, vol.31, n.113, pp. 1319-1335.

ALVES, João Roberto Moreira. As bases legais da educação a distância no Brasil. ABMES - Associação Brasileira de Mantenedoras do Ensino Superior, Revista de Estudo n. 26. Disponível em: <http://www.abmes.org.br/Publicacoes/Revista_Estudos/ estud26/joao.htm>. Acesso em: 20 Jun. 2012. 
ALVES, João Roberto Moreira. A história da educação a distância no Brasil. IPAE Instituto de Pesquisas Avançadas em Educação, Ana 16, Revista n. 86, 2007. Disponível em: <http://www.ipae.com.br/pub/pt/cme/cme_82/index.htm>. Acesso em: 20 Jun. 2012.

BELLONI, Maria Luiza. Educação a distância. 5. Ed. Campinas, SP: Autores Associados, 2009. (Coleção educação contemporânea).

BRASIL. Constituição da República Federativa do Brasil, de 05 de outubro de 1988. Diário Oficial da União, Brasília, DF, 05 out. 1988.

BRASIL. Decreto n. 2.494, de 10 de fevereiro de 1998. Regulamenta o art. 80 da Lei no 9.394, de 20 de dezembro de 1996, e dá outras providências. Diário Oficial da União, Brasília, DF, 11 fev. 1998.

BRASIL. Decreto n. 5.622, de 19 de dezembro de 2005. Regulamenta o art. 80 da Lei no 9.394, de 20 de dezembro de 1996. Estabelece as diretrizes e bases da educação nacional. Diário Oficial da União, Brasília, DF, 20 dez. 2005.

BRASIL. Decreto no 5.800, de 8 de Junho de 2006. Dispõe sobre o sistema Universidade Aberta do Brasil. Diário Oficial da União, Brasília, DF, 9 jun. 2006.

BRASIL. Decreto no 6.303, de 12 de dezembro de 2007 - Sistema Universidade Aberta do Brasil. Disponível em: <http://www.planalto.gov.br/ccivil_03/_Ato20072010/2007/decreto/D6303.htm >.Acesso em: 25 Jun. 2012.

BRASIL. Lei $\mathbf{n}^{\mathbf{0}}$ 9.394, de 20 de dezembro de 1996. Estabelece as diretrizes e bases da educação nacional. Diário Oficial da União, Brasília, DF, 23 dez. 1996.

BRASIL. Projeto de Lei $\mathbf{n}^{\mathbf{0}} \mathbf{1 0 . 1 7 2}$, de 9 de janeiro de 2001. Plano nacional de Educação para o Decênio 2001-2010. Disponível em: portal.mec.gov.br/arquivos/pdf/pne.pdf. Acesso em: 12 set. 2012.

CORTINHAS, Maristela Sobral. Educação a distância no ensino superior: reflexões sobre o processo de inclusão/exclusão. Disponível em: <http://www.catedra.ucb.br/. Acesso em 15 Jul. 2012.

COSTA, Maria Luisa Furlan. Políticas Públicas para o Ensino Superior a Distância e a Implementação do Sistema Universidade Aberta do Brasil no Estado do Paraná. Tese de Doutorado, UNESP, Araraquara, 2010.

COSTA, Maria Luisa Furlan. História e Políticas Públicas para o Ensino Superior a Distância: O Sistema Universidade Aberta do Brasil em Questão. Revista Histedbr On-Line. n. 45. março/2012, p. 282-295.

COSTA, Maria Luisa Furlan. Educação a Distância no Brasil: Perspectiva Histórica. In: COSTA, M. L. F.; ZANATTA, R. M. Educação a Distância no Brasil: aspectos históricos, legais, políticos e metodológicos. 2 ed., Maringá: Eduem, 2010, p. 7-22.

Darcy Ribeiro. Candido Alberto Gomes (organizador). Recife: Fundação Joaquim Nabuco, Editora Massangana, 2010.

DOURADO, Luiz Fernandes; SANTOS, Catarina de Almeida. EAD no Contexto Atual e o PNE 2011-2020: IN: DOURADO, L. F. (Org.). Plano Nacional de Educação (20112020): Avaliação e Perspectiva. Belo Horizonte: Autêntica, 2011.

Educação a Distância no Brasil: aspectos históricos, legais, políticos e metodológicos. Maria Luisa Furlan Costa, Regina Maria Zanatta (organizadoras). - 2. Ed. Maringá: Eduem, 2010. 
GUIMARÃES, P. V. A Contribuição do Consórcio Interuniversitário de Educação Continuada e a Distância - BrasilEad - para o Desenvolvimento da Educação Nacional. Em Aberto, Brasília, DF, ano 16, n. 70, p. 28-33, abr./jun., 1996.

KEARSLEY, Greg; MOORE, Michael. Educação a Distância: uma visão integrada. (Tradução Roberto Galman). São Paulo: Cengage Learning, 2010.

MAIA, Carmem. ABC da EaD. 1. Ed. São Paulo: Pearson Prentice Hall, 2007.

MATIAS-PEREIRA, José. Educação Superior a Distância, Tecnologia de Informação e Comunicação e Inclusão Social no Brasil. Revista de Educação Política de las Tecnologias de la Información y Comunicación. Vol. XII, n. 2, mayo/ago, 2010. Disponível em: www.eptic.com.br. Acesso em: 20 Out. 2012.

MORAN, Jose Manuel. Questões legais para o Avanço dos Referenciais de Qualidade em EAD. Colabor@ Revista Digital do CVA - Ricesu. vol 5, n. 17, Jul., 2008. Disponível em: http://pead.ucpel.tche/revistas/index.php. Acesso em: 20 Out. 2011.

PIMENTEL, Nara Maria. Tese de Doutorado. Educação aberta e a distância: análise das políticas públicas e da implementação da educação a distância no Ensino Superior do Brasil a partir das experiências da Universidade Federal de Santa Catarina e da Universidade Aberta de Portugal. Disponível em: http://repositorio.ufsc.br/bitstream/handle/123456789/88884/227971.pdfsequence=1.

Acesso em: 9 Out. 2012.

SAVIANI, Dermeval. O Plano de Desenvolvimento da Educação: análise do projeto do MEC. Educ. Soc. Campinas, v. 28, n. 100, Oct 2007. Disponível em: http:www.scielo.br/scielo.php?script=sci_arttext\&pid=S01073302007000300027\&ln.

Acesso em: 20 Dez. 2012.

VILAÇA, Márcio Luiz Corrêa. Educação a Distância e Tecnologias: conceitos, termos e um pouco de história. Revista Magistro. v. 1, n. 2, 2010.

Notas

\footnotetext{
* O presente texto é um recorte do resultado de um projeto de dissertação (publicada em 2013), desenvolvida pela autora e sua orientadora do Curso de Mestrado em Educação da Universidade Estadual de Maringá (UEM), que analisou a questão da qualidade no Ensino Superior na Modalidade a Distância.

** Graduada em Pedagogia (UNIPAR), e, Ciências Sociais (UMESP); Especialista em: Planejamento Ambiental (FECILCAM), Educação a Distância (UEM), e, Gênero e Diversidade (UEPG); Mestre em Educação (UEM). Professora da rede pública e Coordenadora de Polo da Universidade Aberta do Brasil.

*** Graduada em História (UEM), Mestre em Educação (UEM), Doutora em Educação (UNIESP), Professora do Departamento de Fundamentos da Educação - DFE, Professora do Programa de Pós-Graduação em Educação - PPE, Diretora do Núcleo de Educação a Distância - NEAD, Coordenadora do Programa Universidade Aberta do Brasil - UAB-UEM, Presidente do Fórum Nacional de Coordenadores UAB.
} e do Distrito Federal, constitui-se em Estado Democrático de Direito (BRASIL, 1988). 
2 Lei $\mathrm{n}^{\circ}$ 9.394, de 20 de dezembro de 1996, estabelece as diretrizes e bases da educação nacional (BRASIL, 1996).

3 A universidade com direito de ser considerada a primeira dedicada ao ensino a distância é a University of South Africa, que iniciou seu sistema de EaD logo após o fím da segunda guerra mundial (KEARSLEY; MOORE, 2010).

4 Darcy Ribeiro: Antropólogo, político, professor, escritor, idealizador e primeiro reitor da Universidade Nacional de Brasília (UNB), Relator no Senado do Projeto da LDBEN 9394/96; Fundador da Universidade Estadual do Norte Fluminense (UENF); Participou dos projetos de idealização da Universidade Aberta do Brasil e da Escola Normal Superior (GOMES, 2010, p. 133-135).

$5 \quad$ A SEED foi criada em 1996 e extinta em 2011.

6 Decreto n. ${ }^{\circ}$ 2.494, de 10 de fevereiro de 1998: Primeiro decreto que regulamenta a modalidade a distância.

7 Decreto n. ${ }^{\text {0 }} 5.622$, de 19 de dezembro de 2005: Substituiu o primeiro decreto que regulamenta a modalidade a distância no Brasil, regulamentando as novas diretrizes para EaD.

8 Decreto n. ${ }^{\circ}$ 5.800, de 8 de Junho de 2006: Institui o Sistema Universidade Aberta do Brasil - UAB, seus objetivos e finalidades socioeducacionais.

9 ABRAEAD: Anuário Brasileiro Estatístico de Educação Aberta e a Distância é considerado o maior levantamento de dados com circulação nacional, com sua primeira edição em 2004 (ABRAEAD, 2008, p. 14).

Recebido: julho-13 Aprovado: outubro-14 